\title{
Epidemiological, clinical and therapeutic profile of the umbilical cord prolapse at the Befelatanana University Hospital Centre of Obstetric Gynecology in Antananarivo, Madagascar
}

\section{Randriamahavonjy R. ${ }^{1}$, Rakotonirina Andriamaro M. ${ }^{2 *}$, Ratsiatosika Andriamanetsiarivo T. ${ }^{2}$ Housni I. ${ }^{2}$, Abasse B. A. ${ }^{2}$, Rakototiana A. F. ${ }^{3}$, Andrianampanalinarivo H. R. ${ }^{2}$}

\begin{abstract}
${ }^{1}$ Department of Obstetrics and Gynecology, University Hospital Center of Soavinandriana, Antananarivo, Madagascar ${ }^{2}$ Department of Obstetrics and Gynecology, The Befelatanana University Hospital of Obstetric Gynecology in Antananarivo, Madagascar

${ }^{3}$ Department of Urology, University Hospital Center of Joseph Ravoahangy Andrianavalona, Antananarivo, Madagascar
\end{abstract}

Received: 26 June 2018

Accepted: 26 July 2018

\section{*Correspondence:}

Dr. Rakotonirina Andriamaro M.,

E-mail: andriamarorakotonirina@gmail.com

Copyright: (c) the author(s), publisher and licensee Medip Academy. This is an open-access article distributed under the terms of the Creative Commons Attribution Non-Commercial License, which permits unrestricted non-commercial use, distribution, and reproduction in any medium, provided the original work is properly cited.

\section{ABSTRACT}

Background: Umbilical cord prolapse is a major obstetrical emergency that threatens the fetal prognosis during labor. The objective of this study was to describe the epidemiologic and clinical profile of pulsatile cord prolapse at the Befelatanana University Hospital of Obstetric Gynecology.

Methods: It is about a retrospective cross-sectional study conducted at the Befelatanana University Hospital of Obstetrics and Gynecology in Antananarivo over a period of 3 years, from January 1st, 2012 to December 31st, 2014. We have identified all cases of umbilical cord prolapse. We studied obstetric, neonatal and maternal parameters.

Results: We found 70 cases of pulsatile umbilical cord prolapse, a prevalence of $0.28 \%$ of deliveries. The average age of the patients was $28 \pm 3.2$ years with extremes ranging from 18 to 43 years. Multiparous women predominated with $(51.43 \%)$ Pregnancy was long term, with $71.43 \%$ of cases associated with placenta praevia, lateral prolapse of the limb, long cord and contracted pelvis. The prolapse of the cord was 1 st degree with $44.29 \%$ of cases. All patients had received $(100 \%)$ of oxygen therapy. Almost all patients were caesarized $(95.71 \%)$. Neonatal complications were represented by admission to neonatal intensive care unit (32.86\%), perinatal asphyxia (31.43\%), prematurity $(28.57 \%)$, neonatal infection $(4.29 \%)$ and neonatal death $(10 \%)$.

Conclusions: The umbilical cord prolapse is relatively rare. Fetal extraction in the shortest possible time, especially when the cord is externalized, which is the main determining factor of neonatal prognosis.

Keywords: Madagascar, Obstetrical emergency, Prevalence, Umbilical cord prolapse

\section{INTRODUCTION}

Umbilical cord prolapse is defined as the fall at the time of rupture or rupture of the membranes of a cord loop in front of the presentation.
It is an important and unpredictable cause of perinatal mortality. Its gravity lies in the rapid onset of neonatal prognosis; it is the most serious funicular movement. This is the same type of extreme obstetric emergency that darkens the fetal prognosis without burdening the mother's. ${ }^{1}$ Its incidence varies between 1.5 and two 
prolapses per 1,000 births. $^{2}$ In Africa, including Madagascar, which is a developing country, neonatal death remains very high. Over every 1,000 live births, twenty-four die between zero and one month and twentyfour between one and twelve months. Perinatal asphyxia is one of the first causes of cord prolapsed. ${ }^{3}$

Present study aims to describe the epidemiological and clinical profile of pulsatile cord prolapse at the University Hospital of Gynecology and Obstetrics of Befelatanana.

\section{METHODS}

It is about a retrospective cross-sectional study conducted at the Befelatanana University Hospital of Obstetrics and Gynecology in Antananarivo over a period of 3 years, from January $1^{\text {st }} 2012$ to December $31^{\text {st }} 2014$ a reference level III maternity Centre located in the centre of town. Of the capital.

We included all pregnant women whose term of pregnancy is more than or equal to 32 weeks of amenorrhea (SA), who had procured the pulsatile umbilical cord prolapse (the cord is in front of the presentation, the membranes are broken) and having delivery at Befelatanana University Hospital Centre of Obstetric Gynecology (BUHCOG). All ventral decubitus of the cord has been excluded. Data were collected from: parturient records, operative and delivery records, and statistics records.

The variables analyzed are: mother's age, parity, mode of admission (direct or referred entry), occupation, level of education, distance between the site of rupture of the membranes and the Hospital, number of antenatal care consultations (ANC), fetal presentation, term of pregnancy in weeks of amenorrhea (SA), number of fetuses, associated pathologies such as: placenta praevia, lateral prolapse of the limb, uterine myoma, praevia tumor, hydramnios, contracted pelvis and other cord abnormalities such as long cord, circular or node presence, degree of prolapse $\left(1^{\text {st }}, 2^{\text {nd }}\right.$ or $3^{\text {rd }}$ degree $)$, cervical dilatation at the time of prolapse, color of amniotic fluid, management, APGAR score at the $5^{\text {th }}$ minute of delivery, birth weight, route of delivery, fetal complications. The exploitation of the data was carried out using the software R.

\section{RESULTS}

During the study period, there were 70 cases of pulsatile umbilical cord prolapse out of 25033 deliveries, a prevalence of $0.28 \%$. The average age of parturients was $28 \pm 3.2$ years with extremes ranging from 18 to 43 years. Housewives were the most numerous of (44.28\%) and most of them had completed high school (37.14\%). Umbilical cord prolapse mainly involved women under 30 , accounting for $62.85 \%$ of cases. The average parity was 6 , with a predominance of multiparas of $51.43 \%$. According to the mode of admission: $58.57 \%$ of parturients come themselves to the Hospital as well as 41, $43 \%$ of the cases were referred. The distance between the rupture site of the membranes and BUHCOG was less than $10 \mathrm{~km}$ for most parturients (54 cases) which is $77.14 \%$; while it was more than $10 \mathrm{~km}$ of which $20 \%$ of cases (14 parturients). The average number of antenatal care visits observed in our series was six and with what $34.29 \%$ of the cases was less than 4 .

\section{Table 1: Epidemiological and clinical characteristics} of patients with cord prolapse.

\begin{tabular}{|c|c|c|c|}
\hline Parameters & Division & $\begin{array}{l}\text { Number } \\
(\mathrm{n}=70)\end{array}$ & $\begin{array}{l}\text { Rate } \\
(\%)\end{array}$ \\
\hline \multirow{4}{*}{ Age (years) } & $<20$ & 5 & 7.1 \\
\hline & $20-30$ & 39 & 55.7 \\
\hline & $30-40$ & 19 & 27.1 \\
\hline & $\geq 40$ & 7 & 10.1 \\
\hline \multirow{4}{*}{ Profession } & Housewife & 31 & 44.2 \\
\hline & Primary sector & 23 & 32.8 \\
\hline & Secondary sector & 10 & 14.2 \\
\hline & Tertiary sector & 6 & 8.5 \\
\hline \multirow{4}{*}{$\begin{array}{l}\text { Education } \\
\text { level }\end{array}$} & Illiterate & 4 & 5.7 \\
\hline & Elementary & 22 & 31.4 \\
\hline & Secondary & 26 & 37.1 \\
\hline & College & 18 & 37.1 \\
\hline \multirow{3}{*}{ Parity } & Primiparous & 17 & 24.2 \\
\hline & 2-4 parity & 17 & 24.2 \\
\hline & Multiparous & 36 & 51.4 \\
\hline \multirow{2}{*}{$\begin{array}{l}\text { Gestational } \\
\text { age }(\mathrm{SA})\end{array}$} & $32-37$ & 20 & 28.5 \\
\hline & $\geq 37$ & 50 & 71.4 \\
\hline \multirow{2}{*}{$\begin{array}{l}\text { Mode of } \\
\text { admission }\end{array}$} & Direct admission & 41 & 58.5 \\
\hline & Referred & 29 & 41.4 \\
\hline \multirow{3}{*}{$\begin{array}{l}\text { Number of } \\
\text { ANC* }\end{array}$} & 0 & 9 & 12.8 \\
\hline & $1-4$ & 24 & 34.2 \\
\hline & $\geq 4$ & 37 & 52.8 \\
\hline \multirow{3}{*}{$\begin{array}{l}\text { Fetal } \\
\text { presentation }\end{array}$} & Cephalic & 41 & 58.5 \\
\hline & Transversal & 16 & 22.8 \\
\hline & Breech & 13 & 18.5 \\
\hline \multirow{2}{*}{$\begin{array}{l}\text { Number of } \\
\text { fetus }\end{array}$} & Singleton & 61 & 87.1 \\
\hline & Twins & 9 & 12.8 \\
\hline \multirow{2}{*}{$\begin{array}{l}\text { Dilation of } \\
\text { the cervix }\end{array}$} & Complete & 3 & 4.2 \\
\hline & Uncomplete & 67 & 95.7 \\
\hline \multirow{4}{*}{$\begin{array}{l}\text { Associated } \\
\text { pathologies }\end{array}$} & Placenta prævia & 1 & 1.4 \\
\hline & $\begin{array}{l}\text { Lateral prolapse } \\
\text { of limb }\end{array}$ & 7 & 10 \\
\hline & Long cord & 1 & 1.4 \\
\hline & Obstructed labour & 1 & 1.4 \\
\hline \multirow{3}{*}{$\begin{array}{l}\text { Degree of } \\
\text { prolapse }\end{array}$} & $1^{\text {st }}$ degree & 31 & 44.2 \\
\hline & $2^{\text {nd }}$ degree & 22 & 31.4 \\
\hline & $3^{\text {rd }}$ degree & 17 & 24.2 \\
\hline \multirow{2}{*}{$\begin{array}{l}\text { Amniotic } \\
\text { fluid color }\end{array}$} & Clear & 22 & 31.4 \\
\hline & Meconium & 38 & 54.2 \\
\hline
\end{tabular}

Among the presentations from breech births, we noted nine cases of $(12.80 \%)$ of complete breech births and four cases $(5 \%)$ of uncompleted breech births. Full-term pregnancy was $71.43 \%$ of the cases. Among these 
umbilical cords prolapses, nine cases occurred in twins pregnancy, which is $12.86 \%$ of cases, six of them occurred in the second twins. No cases of hydramnios, myoma praevia, or other cord abnormalities were noted. The umbilical cord prolapse was at $1 \mathrm{st}$ degree, that is to say, the cord was intravaginal in $44.29 \%$ of cases. We noted that the average cervical dilation was $6 \mathrm{~cm}$. In addition, three cases of cord prolapse, $4.29 \%$ were diagnosed with complete dilatation. The amniotic fluid was clear in $45.71 \%$ of cases (32 parturients) and meconial in $54.29 \%$ (Table 1).

Table 2: Behaviour with patients with cord prolapse.

\begin{tabular}{|llll|}
\hline \multirow{3}{*}{ Parameters } & Division & $\begin{array}{l}\text { Number } \\
(\mathrm{n}=70)\end{array}$ & $\begin{array}{l}\text { Rate } \\
(\%)\end{array}$ \\
\cline { 2 - 4 } Behaviour & Oxygen therapy & 70 & 100 \\
\cline { 2 - 4 } & $\begin{array}{l}\text { Trendelenburg } \\
\text { position }\end{array}$ & 64 & 91.4 \\
& \begin{tabular}{l} 
Bladder filling \\
\cline { 2 - 3 } Delivery
\end{tabular} & 42 & 60 \\
\cline { 2 - 4 } route & Breech presentation & 44 & 62.8 \\
\hline & Cesarean & 67 & 95.7 \\
\hline
\end{tabular}

All parturients had benefited from oxygen therapy. We found that $60 \%$ of parturients had bladder filling. We found $62.86 \%$ refoulement of the fetuses during our study. The average time between cord prolapse and fetal extraction was 63.50 minutes. Sixty-seven parturients, or $95.71 \%$ of the cases, had a caesarean section. The rests of the three $(4.28 \%)$ were vaginal delivery with complete cervical dilatation (Table 2).

Table 3: Neonatal complications.

\begin{tabular}{|llll|}
\hline Parameters & $\begin{array}{l}\text { Division } \\
\text { Number }\end{array}$ & $\begin{array}{l}\text { Rate } \\
\text { (n) }\end{array}$ \\
\hline \multirow{2}{*}{$\begin{array}{l}\text { Neonatal } \\
\text { complications } \\
\text { neonatal } \\
\text { intensive care } \\
\text { unit }\end{array}$} & 23 & 32.8 \\
\cline { 2 - 4 } & $\begin{array}{l}\text { Perinatal } \\
\text { asphyxia }\end{array}$ & 22 & 31.4 \\
\cline { 2 - 4 } & $\begin{array}{l}\text { Prematurity } \\
\text { Neonatal death }\end{array}$ & 20 & 28.5 \\
\hline & $\begin{array}{l}\text { Neonatal } \\
\text { infections }\end{array}$ & 3 & 10 \\
\hline
\end{tabular}

The neonatal complication was dominated by perinatal asphyxia (Apgar score $<7$ at the fifth minute) of $31.43 \%$. Other complications were admission to neonatal intensive care unit $(32.86 \%)$, prematurity $(28.57 \%)$, neonatal infection (4.29\%) and neonatal death (10\%) (Table 3).

\section{DISCUSSION}

In present study case, the prevalence of pulsatile umbilical cord prolapse was $0.28 \%$. This percentage is identical to what found at the same Hospital by Rakotozanany and al in 2010 finding a respective rate of
$0.27 \%$ and Traoré in Mali in $2006(0.27 \%) .{ }^{1,4}$ In developed countries, our result is slightly higher than discovered by Gannard $\mathrm{P}$ and al $(0.18 \%)$ in France, the United States of America $(0.2 \%)$ and Singapore $(0.12 \%) .^{5-7}$ But in reality the frequency of the cord prolapse varies according to factors.

The average age of the patients was $28 \pm 3.2$ years old with a prevalence of the age group between 25 to 30 years (28.57\%). These results are matching with those of the BUHCOG study in 2010 conducted by Rakotozanany and al, who found an average age of 28 years old, Gannard P and al (30 years old) with a predominance of the same age group. ${ }^{4,5}$ In the literature, there is no direct influence of age in the occurrence of cord prolapse; it could be indirectly interfere with risk factors. Present study found that $51.43 \%$ of women were multiparous and $24.29 \%$ were primiparous. This rate is comparable to Rakotozanany's (51\%) and slightly lower than the Dufour's and al (76\%)., ${ }^{4,8}$ Nearly all authors in the literature believe that multiparity due to excessive laxity of the uterine wall and delayed presentation is one of the risk factors favoring cord prolapse. ${ }^{1}$

Prolapse is five times more common in multiparous than in primiparous. ${ }^{9}$ Statistically, $58.57 \%$ of our parturients were admitted directly to BUHCOG. However, $41.43 \%$ of them were referred by basic health care centre, suburb maternity care, midwives and doctors practicing liberally in the neighborhoods. Kolas and al, found a $75.6 \%$ referral rate in 2006 in the literature several authors found that the fetal prognosis is poor when cord prolapse occurs outside the Hospital and requires transfer. ${ }^{10,11}$ Regarding the distance between the rupture site of membranes and the BUHCOG, this distance was less than $10 \mathrm{~km}$ for most of our parturients, or $77.14 \%$ of cases. This is probably due to the fact that when umbilical cord prolapse occurs after rupture of the water pocket, and if the patient lived in a distance away from the BUHCOG, more than $10 \mathrm{~km}$ and with the difficulties of the organization of a transfer, the fetus would have had time to die; as a result, these fetuses would have been excluded from this study. More than half of the women $(52.86 \%)$ had attended more than four prenatal care consultations; $34.29 \%$ one to four prenatal care consultation and $12.86 \%$ had not performed antenatal care consultation. Antenatal consultations are classified as prophylactic measures that may decrease the incidence of cord prolapse. Indeed, contracted pelvis and vicious breech presentations need to be screened during prenatal care consultations. ${ }^{12}$ Although cord prolapse is in rare condition in cephalic presentations, statistically, we have identified more than half of our cases with frequency of $58.57 \% .{ }^{13}$ This rate matches to the Gannard $\mathrm{P}$ and team with a value of $57 \% .^{5}$ In the breech presentations, the prolapse is also quite common, especially in case of complete breech birth, we noted from our part $12.80 \%$ of complete breech birth and $5.77 \%$ and $18.57 \%$ of uncompleted breech birth in general while in Morocco the percentage of breech birth presentation was $31.95 \% .^{13,14}$ In cross-sectional 
presentations, cord prolapse is common: $32 \%$ according to Dao and al. ${ }^{15}$ In present study, there was a $22.86 \%$ presentation of the shoulder. The majority of our parturients, $71.43 \%$, had a gestational age of $\geq 37$ weeks of amenorrhea and $28.57 \%$ had a pregnancy that was not complete, which meet up with the literature data. Traoré and al. Found $29.7 \%$ of non-term pregnancies and $72 \%$ cases of prolapse at $37 \mathrm{AS}$ and plus. ${ }^{1}$ Dufour and his team reported a rate close to ours because $26 \%$ of parturients had a lower gestational age at $37 \mathrm{AS} .^{5}$ Concerning the number of fetuses, multiple pregnancies, mainly twin pregnancies accounted for $12.86 \%$ of cases and in $66.66 \%$ of the cases, prolapse was for the second twins. Our results are inferior to those of the literature. Traore Y and al found a $23.4 \%$ frequency of twin pregnancies and in $91 \%$ of cases, prolapse was in the second twins. ${ }^{1}$ This is why explained that after the birth of the first twin, the second twin lies off in the uterine cavity insufficiently retracted.

The accommodation is defective, thus favoring irregular presentations and prolapse. ${ }^{1}$ For the abnormalities associated with cord prolapse, the prevalence of placenta praevia was $1.43 \%$. This rate is relatively lower compared to that reported in the literature. Guikotavy and his team found a prevalence of the placenta praeviaprolapse association of $11 \% .{ }^{16} \mathrm{We}$ did not find any praevia, uterine myoma, and hydramnios in present study, although these factors are considered to be associated with umbilical cord prolapse but only one case of contracted pelvis $(1.43 \%)$ was found.

Respectively $44.29 \%, 31.43 \%$ and $24.29 \%$ of cases, umbilical cord prolapse was at $1^{\text {st }}, 2^{\text {nd }}$ and $3^{\text {rd }}$ degree. The 1 st degree of cord prolapse was thus the most frequent. Randrianantoanina and al found $57.14 \%$ of first degree cord prolapse and an identical rate of $21.42 \%$ for $2^{\text {nd }}$ and $3^{\text {rd }}$ degree cord prolapsed. ${ }^{13}$

In present study, all cases of prolapse were diagnosed by vaginal touch and statistically, the average cervical dilation was $6 \mathrm{~cm}$. This figure is more or less similar to what Alouini $\mathrm{S}$ and collaborators found in France who found an average cervical dilation of $7 \mathrm{~cm} .{ }^{17}$ In present study, $4.29 \%$ of cases were diagnosed on a fully dilated cervix. More than half of the women,

$54.29 \%$, had a meconium amniotic fluid at the time of diagnosis versus $45.71 \%$ a clear amniotic fluid. A study conducted by Bouayad $\mathrm{S}$ in Morocco found clear amniotic fluid in $58.7 \%$ of the cases. ${ }^{18}$

Depending on the action to be taken, as soon as the diagnosis was confirmed, all parturients were put on nasal oxygen therapy at a rate of 6 liters per minute to avoid fetal hypoxia. $91.43 \%$ (64 cases) of women were put in Trendelenburg position. To maintain the high presentation, the manual delivery of it avoids any cord compression until fetal extraction. $62.86 \%$ of our parturients had benefited from this movement. $60 \%$ of women had benefited from bladder filling which is a simple way of waiting. Its simplicity of use and reliability justify its teaching and its use especially in countries with low Hospital infrastructure like Madagascar. Randrianantoanina $\mathrm{F}$ and al noted in their study that all parturients were placed in Trendelenburg position and under oxygen therapy, $85.71 \%$ received bladder filling; this rate is significantly higher than ours. $62.86 \%$ is repressed. ${ }^{13} 95.71 \%$ of parturients were caesarized. This rate is higher compared to those reported by other authors. Traoré $\mathrm{Y}$ found a caesarean section rate of $61.7 \%$, Alouini S a rate of $84 \%$ and $87.5 \%$ for Rozilla S. ${ }^{1,17,18}$ The vaginal delivery rate was only $4.29 \%$. Funicular prolapse is a typical obstetric emergency that is life-threatening for the fetus and usually requires surgical removal. However, the low pathway is currently accepted especially in multiply dilated whole with committed cephalic presentation or if the fetus is dead or not viable. ${ }^{19}$

Neonatal complications were represented by admission to neonatal intensive care unit $(32.86 \%)$, perinatal asphyxia $(31.43 \%)$, prematurity $(28.57 \%)$, neonatal infection $(4.29 \%)$ and neonatal death $(10 \%)$. These rates match those found by Rakotozanany: admission to neonatal intensive care unit (33\%), perinatal asphyxia (31\%), prematurity $(29 \%)$, neonatal infection $(4 \%)$ and neonatal death $(10 \%){ }^{7}$ However, this rate of perinatal asphyxia is lower than the Rozilla S and his team which was $61 \% .^{18}$

\section{CONCLUSION}

The prevalence of umbilical cord prolapse in the BUHCOG has remained stable for some years. It is still an obstetric-surgical emergency despite its relatively low frequency. The treatment, based on the rapid extraction of these suffering fetuses, is done by caesarean section which remains the treatment of choice if the delivery is not imminent by natural way. During labor, conventional precautions should be continued to prevent cord prolapse during artificial rupture of membranes. The reduction of the morbidity and fetal mortality rate in relation to this pathology requires improvement of the evacuation conditions and the technical plateau.

Funding: No funding sources Conflict of interest: None declared

Ethical approval: Not required

\section{REFERENCES}

1. Traore Y, Dicko TF, Teguete B, Mulbah JK, Adjobi R, Nguessan E, Tegnan A. Cord Prolitis: Aetiological Factors and Fetal Prognosis for 47 Collected Cases in a Reference Health Center. Mali Medical. 2006

2. Boyle JJ, Katz VL. Umbilical cord prolapse in current obstetric practice J Reprod Med. 2005;50:303-6. 
3. National Institute of Statistics (Instat) and ICF Macro. Demographic and Health Survey of Madagascar 2008-2009. Antananarivo, Madagascar: Instat et ICF Macro..

4. Rakotozanany B, Randriambololona DMA, Razafimadimby F, Rakotomalala NZ, Randriambelomanana JA, Andrianampanalinarivo HR. Neonatal prognosis of the procidence of the pulsatile umbilical cord at Befelatanana hospital Madagascar. Med Tropic Health. 2015;25:434-5.

5. Gannard P, Ramanah R, Cossa S, Mulin B, Maillet R, Riethmuller D. Cord Prolitis: About a 23-year series of activities. J Gynecol Obstet biol Reproduc. 2012;41:574-83.

6. Prabulos AM, Philipson EH. Prolapse of the umbilical cord. Is the delay between diagnosis and delivery critical? J Reprod Med. 1998;43:129-32.

7. Tan WC, Tan LK, Tan HK, Tan AS. Audit of emergency "caesarean" caesarean sections due to cord prolapse in terms of response time and perinatal outcome. Ann Acad Med Singapore. 2003;32:63841.

8. Dufour P, Vinatier D, Bennani S, Tordjeman N. Cord Procidence: Literature Review of 50 Observations. J Gynecol Biol Reprod. 1996;25:8415.

9. Jamain B. Obstetrical practice. Paris: Masso; 2009:5, 27, 64, 89,93.

10. Kola S. Umbilical Cord Procidence: Factor, Aetiology and Fetal Prognosis. About 60 cases identified at Bamako District Teaching Hospital (MALI). Bamako;2006-M 325.

11. Driscoll J A, Sadan O, Van Gelderen J, Holloway G A.Cord prolapse. Can we save more babies J Case reports? Br J Obstét Gynécol. 2007;481:29.

12. Prabulos AM, Philipson EH.Umbilical cord prolapsed. Is the time from diagnosis to delivery critical? J Reprod Med. 2008;2:129-32.
13. Randrianatoanina F, Rakotosalama D, Ravelosoa E, Rakotondramanana N. Interests of bladder filling during pulsatile umbilical cord procidence on the 14 cases observed at CHUA Befelatanana maternity ward. Med trop 2007;68:58-60.

14. Bouayad S. The procidence of the umbilical cord about the 97 cases. University of Sidi Mohammed Ben Abdellah. Morocco;2011:103/11.

15. Dao B. Umbilical Cord Procidence: Risk Factor and Prognosis in African Settings. Med Black Afr. 2002;7:351-4.

16. Guikovati JP, Dellenbach P, Lewin D. The procidence of the cord and limbs. In: Vokaer. Treaty of obstetrics. Paris: Masson, 1985, 473-476.

17. Alouini S, Mesnard L, Megier P, Lemaire B, Coly S, Desroches A. Cord Procidence: Obstetrical Management and Neonatal Consequences. J Gynecol Obstet Biol Reproduct. 2010;39:471-7.

18. Rozilla S, Khan, Tahira N. Umbilical cord prolapsed. A review of diagnosis to delivery interval on perinatal and maternal outcome. Department of obstetrics and Gynaecology, Aga Khan University Hospital, Pakistan;2007:2-4.

19. Berlan M, Magnin G. Premature rupture of membranes. EMC Obstetrics. 2004;4(4):3.

Cite this article as: Randriamahavonjy R, Andriamaro RM, Andriamanetsiarivo RT, Housni I, Abasse BA, Rakototiana AF, et al. Epidemiological, clinical and therapeutic profile of the umbilical cord prolapse at the Befelatanana University Hospital Centre of Obstetric Gynecology in Antananarivo, Madagascar. Int J Reprod Contracept Obstet Gynecol 2018;7:3441-5. 